\title{
Quantifying climate-productivity relationships: a modelling approach in Nothofagus forests
}

\author{
Christian Salas ${ }^{1,1}$ \\ ${ }^{1}$ Universidad Mayor
}

May 5, 2020

\begin{abstract}
Unique combinations of geographic and environmental conditions make quantifying the importance of factors that influence forest productivity difficult. We aimed to model the height growth of dominant Nothofagus alpina trees in Chile, as a proxy for forest productivity, by building a dynamic model that consider topography, habitat type, and climate conditions. We used growth data of 169 dominant trees sampled throughout south-central Chile (36-41 S). After accounting for the interaction between aspect, slope, and elevation, as well as the effect of habitat type, we found that the precipitation in the driest month and annual mean temperature are the most critical climatic drivers of forest productivity. We predict a reduction of approximately $1 \mathrm{~m}$ in the maximum height of dominant trees given the course of future climate conditions. Our research demonstrates a consequence of climate change in N. alpina-dominated forests: a reduction of tree height growth rates, suggesting a decrease in carbon sequestration too.
\end{abstract}

\section{Hosted file}

graphic.pdf available at https://authorea.com/users/244814/articles/424944-quantifyingclimate-productivity-relationships-a-modelling-approach-in-nothofagus-forests 